International Business Management 13 (8): 318-330, 2019

ISSN: $1993-5250$

(C) Medwell Journals, 2019

\title{
Empowering Leadership as a Predictor for Employees Creativity: The Mediating Role of Intrinsic Motivation
}

\author{
${ }^{1}$ Tariq A.R.M. Alsaadi, ${ }^{2}$ Gamal S.A. Khalifa, ${ }^{1}$ Abuelhassan Elshazly Abuelhassan, \\ ${ }^{1}$ Osama Isaac and ${ }^{1}$ Ibrhim Alrajawi \\ ${ }^{1}$ Faculty of Business and Accountancy, \\ ${ }^{2}$ Faculty of Hospitality and Tourism, Lincoln University College (LUC), Selangor, Malaysia \\ Gamal@lincoln.edu.my, GSK00@fayoum.edu.eg
}

\begin{abstract}
Drawing on leadership theory and social exchange theory, the study investigated the mediating role of Intrinsic Motivation (IM) between the relationship Empowering Leadership (EL) and Employee Creativity (EC) in the Abu Dhabi National Oil Company (ADNOC). The current study adopted SEM to test the study's hypothesis. A sample of 505 employees in the ADNOC was selected randomly. On this representative sample a survey was carried out to find out the extent of EL and IM influence on EC. After testing the direct relationships the researcher had conducted indirect relationships measurements such as the impact of EL on EC via. IM. All the study's hypothesis were supported. Finally, theoretical and managerial implications were discussed.
\end{abstract}

Key words: Empowering leadership, employee creativity, intrinsic motivation, UAE, ADNOC, relationships

\section{INTRODUCTION}

Given increasingly turbulent environments, heightened competition and unpredictable technological change, more and more managers are coming to realize that they should encourage their employees to be creative (Abd-Elaziz et al., 2015; Abou-Shouk and Khalifa, 2017; Khalefa, 2015; Shalley and Gilson, 2004). Considerable evidence indicates that employee creativity can fundamentally contribute to organizational innovation, effectiveness and survival (Amabile et al., 1996; Liu et al., 2016; Mohamud et al., 2017; Shalley et al., 2004). Creativity refers to the production of novel and useful ideas by an individual or by a group of individuals working together (Amabile et al., 1996; Khalifa and Hewedi, 2016; Mohamed et al., 2018; Prather, 2010; Shalley and Gilson, 2004; Shalley et al., 2004). For creativity to occur in organizations, managers need to support and promote it as they are the individuals who are most knowledgeable about which employee research outcomes should be creative and they have considerable influence over the context within which creativity can occur (Khalifa and Abou-Shouk, 2014; Mohamed et al., 2018; Zopiatis and Theocharous, 2018).

Although, a number of studies have investigated the impact of leaders on creativity these investigations have largely focused on issues of leader support (Amabile et al., 2004) and leader-member exchange (Tierney et al., 1999). More recently, researchers have begun investigating broader theories of lead leadership behavior such as transformational leadership theory with mixed results. Noticeably missing from research attention has been empowering leadership, despite suggestions by creativity researchers that scholars focus greater effort on leadership approaches that can address the elemental underpinnings of creativity (Mumford et al., 2002; Alsaadi et al., 2019). Because empowering leadership involves sharing power with a view toward enhancing employee's motivation and investment in their work (Chen et al., 2007; Dong et al., 2015; Hon, 2010; Sharma and Kirkman, 2015; Srivastava et al., 2006; Zhang and Bartol, 2010) there are major reasons (detailed below) to expect empowering leadership to have a positive impact on creativity (Amabile et al., 1996; Amabile et al., 2004; Badran and Khalifa, 2016). Therefore, a major purpose of this study was to build and test theory that addresses the connection between empowering leadership and creativity including several important intervening variables.

The researcher, thus, explored the extent to which empowering leadership works through empowerment to ultimately influence employee intrinsic motivation (Hon, 2010; Zhang and Bartol, 2010). Theoretical arguments have suggested that empowerment in turn, makes a critical contribution to employee creativity by positively affecting an employee's intrinsic motivation (Zhang and Bartol, 2010) but empirical evidence of such an effect has been lacking (Shalley and Gilson, 2004; Shalley et al., 2004).

Corresponding Author: Gamal S.A. Khalifa Faculty of Tourism and Hotels, Fayoum University, Faiyam, Egypt 
This connection is important because conceptually, intrinsic motivation is considered to be a well-established predictor of creativity (Liu et al., 2016; Shalley et al., 2004). Intrinsic motivation is the extent to which an individual is interested in a task and engages in it for the sake of the task itself (Deci and Ryan, 1985; Hon, 2010; Qoura and Khalifa, 2016; Yidong and Xinxin, 2013; Zhao et al., 2011). The researcher posits intrinsic motivation as a mediating element linking empowerment leadership and creativity (Javed et al., 2017; Morsy et al., 2016; Zhang and Bartol, 2010).

Hence, the main objective of the present study is to extend this early and more recent research by examining the role of empowerment leadership and intrinsic motivation in the employee creativity. The contribution is to further increase understanding of the complex relationship between EL and employee creativity by drawing on three major traditions in testing mediation in leadership research. Attention to the mediating mechanisms in the EL follower creativity relationship also highlights important practical benefits. For example if research can specify the proximal processes through which empowering leadership works to increase creativity it could provide organizations with a framework to enhance employee creativity through empowering leadership training. Finally, research on empowering leadership has not been conducted in United Arab Emirates. This study attempts to achieve the following research objectives: to examine the effect of in empowering leadership on employee creativity. To examine the effect of IM on employee creativity. To examine the mediating role of IM on the relationship between empowering leadership and employee creativity.

\section{Literature review}

Empowering leadership and creativity: In view of evidence that leaders can affect employee creativity, several creativity scholars have argued for a closer look at leadership behaviors or styles that might fundamentally address the nature of creative work (Mumford et al., 2002). Such research tends to involve complicated, ill-defined problems for which novel and useful solutions are far from obvious (Mumford et al., 2002; Reiter-Palmon and Illies, 2004). As a result, leaders cannot rely on predefined structures that spell out means or even precise ends. Instead they must encourage employee motivation to solve these problems and yet enable considerable employee latitude. The researcher proposes that one approach to doing, so is empowering leadership (Dong et al., 2015; Hon, 2010; Srivastava et al., 2006; Zhang and Bartol, 2010).

According to Ahearne et al. (2005) conceptualization, empowering leadership involves highlighting the significance of the research, providing participation in decision making, conveying confidence that performance will be high and removing bureaucratic constraints. These behaviors are conceptually highly relevant to creativity. For instance, it is clear from the creativity literature that participation in decision making and perceptions of autonomy are vital preconditions for creative outcomes (Amabile et al., 1996; Amabile et al., 2004). Inherent in the combination of empowering leadership behaviors is delegating authority to an employee, so as to enable the employee to make decisions and implement actions without direct supervision or intervention (Bass, 1985; Boyatzis et al., 1995; Jung et al., 2003). Given the nature of creativity such delegation helps establish a research context wherein an employee is encouraged and empowered to explore diverse creative alternatives before (perhaps) settling on a viable creative solution (Amabile et al., 1996). Zhang and Bartol (2010) defined empowering leadership as the process of implementing conditions that enable sharing power with an employee by delineating the significance of the employee's job, providing greater decision-making autonomy, expressing confidence in the employee's capabilities and removing hindrances to performance (Ahearnen et al., 2005; Chen et al., 2007; Sharma and Kirkman, 2015). Finally, Zhang and Bartol (2010) provided empirical study which revealed that empowering leadership influences positively on employee creativity. Accordingly, the researcher would suggest that:

$\mathrm{H}_{1}$ : empowering leadership positively impacts on employee creativity

Empowering leadership and intrinsic motivation: Intrinsic motivation refers to the extent to which an individual is inner-directed is interested in or fascinated with a task and engages in it for the sake of the task itself (Hon, 2010; Utman, 1997; Yidong and Xinxin, 2013; Zhang and Bartol, 2010). In turn, empowering leadership is defined as the extent to which supervisors express confidence in their employee's abilities, emphasize the significance of their employee's work, involve their employees in decision making and reduce or remove bureaucratic constraints on their employees (Zhang and Zhou, 2014) can foster employee intrinsic motivation (Zhang and Bartol, 2010). Given that intrinsic motivation require for meaningfulness and autonomy and competence (Amabile, 1993; Zhao et al., 2011). Furthermore, intrinsically motivated employee's tend to be cognitively more flexible and persevering (McGraw and Fiala, 1982; Nunnally and Bernstein, 1994; Wiersma, 1992). According to intrinsic 
motivation theory, situational factors such as empowering leadership, exert influence on creativity via. influencing intrinsic motivation (Baer et al., 2003; Hackman and Oldham, 1975; Oldham and Cummings, 1996). The proponents of self-determination theory, Deci and Ryan (1985) suggested that people's intrinsic motivation depends on three factors: capacity and autonomy, most relevant to express confidence and autonomy dimensions of empowering leadership (Ahearnen et al., 2005). Thus, the researcher suggests that:

$\mathrm{H}_{2}$ : empowering leadership positively impacts on employee intrinsic motivation

$\mathrm{H}_{2 \mathrm{a}}$ : intrinsic motivation mediates the relationship between empowering leadership and employee creativity

Intrinsic motivation and creativity: Amabile (1993) suggested that an individual's intrinsic task motivation plays an important role in determining behaviors that may result in creative outcomes. This is because intrinsic motivation "makes the difference between what an individual can do and what an individual will do" (Amabile et al., 1996; Amabile, 1988). As the researcher indicated earlier, the degree of engagement in the creative process varies. If an individual pays little attention to a problem and chooses to minimally engage in its resolution, solutions may not be creative and useful (Zhang and Bartol, 2010; Zhao et al., 2011). On the other hand, creative solutions may be generated when an individual devotes substantial attention to a problem and chooses to fully engage in the creative process that is he or she fully identifies the problem from various perspectives gathers diverse but relevant, information and creates a variety of alternatives (Deci and Ryan, 1985; Yidong and Xinxin, 2013). Simon (1967) indicated that the primary function of intrinsic motivation is the control of attention (Wiersma, 1992; Yidong and Xinxin, 2013). When individuals are intrinsically involved in their research they are more likely to devote all of their attention to the problems they encounter. Such attention directs people to engage in a creative process through self-regulation (Chen et al., 2007). Consequently, intrinsic motivation influences the extent to which an individual will persist in carrying out the creative process (Liu et al., 2016; Shalley and Gilson, 2004; Shalley et al., 2004).

Intrinsic motivation is the extent to which an employee is excited about a work activity and is motivated to engage in it for the sake of the activity itself (Baer et al., 2003; Oldham and Cummings, 1996). To be creative, employees need to be sufficiently interested in a certain problem and/or outcome and in finding ways to solve or achieve it. Consequently, motivation serves to control the attention employees devote to the heuristic issues of creative tasks (Cai et al., 2018; Woodman et al., 1993).

Intrinsically motivated employees are thus more likely to explore new pathways and to take greater risks (Amabile et al., 1996). Consequently, intrinsically motivated employees will be more excited about their research and this increases their creativity (Coelho et al., 2011; Liu et al., 2016; Zhang and Bartol, 2010). Intrinsic motivation has been widely considered in the creativity literature but few studies have empirically tested it and those that have done, so, produced mixed results (Coelho et al., 2011; Shalley et al., 2004; Zhang and Bartol, 2010). The researcher proposes the following:

$\mathrm{H}_{3}$ : intrinsic motivation positively relates to employee creativity

\section{MATERIALS AND METHODS}

\section{Research method}

Overview of the proposed research model: For this study, the hypothesized variables and their relationships in the model have been derived from the available literature of the models and theories that have been prescribed in the literature mentioned above. The proposed model can be seen in Fig. 1. While examining the proposed model it can be seen that EL and IM predicts employees creativity. These relationships are derived from (Ahearnen et al., 2005 ) for EL (Tierney et al., 1999) for IM and (Dong et al., 2017; Zhang and Bartol, 2010) for EC. The proposed extended model examines the relationship between EL, dimension as antecedent variables that explain employee creativity as an output variable among employees in ADNOC in the United Arab Emirates. The proposed model has four hypothesis to test.

Development of instrument: A 22-item questionnaire was developed for this study. Because the respondents were Arab-speaking it was imperative that it be accurately translated from English to Arabic. Back translation was used in this study a procedure commonly used in cross-cultural surveys to test the accuracy of the translation (Brislin, 1970). This study applied multi-item Likert scales which have been widely used in the questionnaire-based perception studies (Lee et al., 2009). Unlike actual usage which is measured using a 7-point ranking scale other variables are subjectively measured using the 7-point Likert scale with 7 being "Strongly Agree" and 1 being "Strongly disagree". For this study, a pre-testing was conducted with 50 employees from 


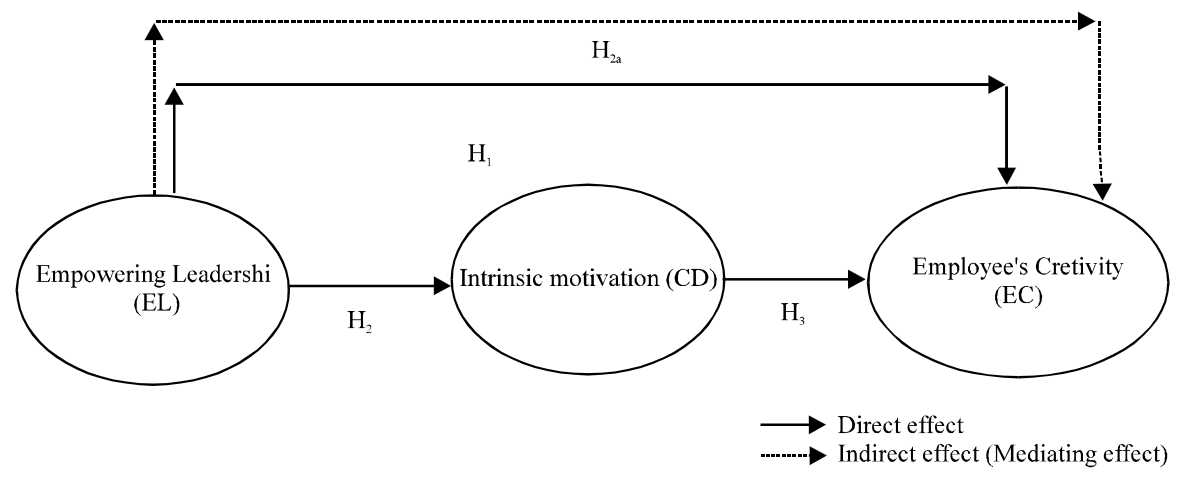

Fig. 1: Proposed research model

ADNOC, UAE to resolve any ambiguity associated with wording or measurement. Then the items were pilot-tested to examine their internal consistency. Out of 630 surveys administered to ADNOC employees, 505 were returned with complete and valid data. In the final questionnaire all items had acceptable reliability as the individual Cronbach's alpha coefficients of the constructs which ranged from $0.710-0.837$ were all greater than the recommended value of 0.7 (Nunnally and Bernstein, 1994).

Data collection: Data collection was conducted using a self-administered study questionnaire which was delivered "in-person" from March 2018 until August 2018 to $\mathrm{ADNOC}$ employees and their immediate supervisors. The employees were approached while in main facilities at ADNOC. A total of 630 questionnaires were distributed with 533 sets returned of which 505 responses were useful for the analysis. The final sample size was considered as adequate (Krejcie and Morgan, 1970; Tabachnick and Fidell, 2012). The $79.7 \%$ response rate is considered very good (Cable amd DeRue, 2002) and above average (Baruch and Holtom, 2008) by comparison with other studies found in the relevant literature. A total of 28 questionnaires were deleted of which 23 cases were removed due to missing data for more than $15 \%$ of the questions and 5 cases involving straight lining.

\section{RESULTS AND DISCUSSION}

\section{Data analysis and results}

Descriptive analysis: The researcher distributed 630 questioners to the ADNOC's employees, the valid questionnaires were received by the researcher are 505 questionnaires by responding rate is $80 \%$. The responding sample $(\mathrm{n}=505)$ consisted of $61.0 \%$ male and $39.0 \%$ female employees. The majority of the participants of public employees range from 25-35 years old. As Table 1 presents that $53.86 \%$ of the respondents were
Table 1: Summary of demographic profile of respondents

\begin{tabular}{lcc}
\hline Variables & Frequency & Valid (\%) \\
\hline Gender & 308 & \\
Male & 179 & 61.00 \\
Female & & 39.00 \\
Age & 41 & \\
$<25$ & 272 & 08.12 \\
$25-35$ & 159 & 53.86 \\
$36-45$ & 33 & 31.49 \\
Over than 45 & & 06.53 \\
Education & 11 & \\
High school & 27 & 02.18 \\
Diploma & 287 & 05.35 \\
Bachelor & 180 & 55.05 \\
Post graduation & & 35.6 \\
Tenure & 36 & \\
$<1$ year & 133 & 07.13 \\
$1-5$ & 197 & 26.34 \\
6-10 & 99 & 39.00 \\
11-15 & 40 & 19.60 \\
More than 15 & & 07.92 \\
\hline
\end{tabular}

aged $25-30$ years, $31.49 \%$ from $36-35$ years. The employees educational level is limited by bachelor and Post Graduation (More than 55 and 36\% had Bachelor and Post Graduation, respectively) and high school (a mere 9\%). Surprisingly, the highest job tenure for those employee's is ranging from 6-years (more that 39\%). On the other hand, the second highest tenure is ranging from $1-5$ years almost $27 \%$.

Measurement model assessment: This study employed Structural Equation Modeling-Variance Based (SEM-VB) through Partial Least Squares (PLS) method to analyze the research model using the software of SmartPLS 3.0 (Ringle et al., 2014). After the descriptive analysis, this study follows the two-stage analytical technique recommended by Anderson and Gerbing (1988) and Hair et al. (2017), starts with the measurement model assessment (validity and reliability), followed by the structural model assessment (testing the hypothesized relationships). Schumacker and Lomax (2004) and Hair et al. (2010) indicate that the two steps assessment 
procedure which includes measurement model and structural model has an advantage over the one step assessment procedure. According to Hair et al. (2017) measurement model specifies how each construct is measured while structural model specifies how the variables are related to each other in the structural model. The main reasons for choosing PLS as a statistical method for this study that for both measurement and structural model PLS offer simultaneous analysis which leads to more accurate estimates (Barclay et al., 1995).

The assessment of measurement model was done through construct reliability as well as validity (including convergent and discriminant validity). For Construct reliability, this study tested the individual Cronbach's alpha coefficients to measure the reliability of each of the core variables in the measurement model. The results indicate that all the individual Cronbach's alpha coefficients ranging from $0.710-0.837$ were higher than the suggested value of 0.7 (Kannana and Tan, 2005; Nunnally and Bernstein, 1994). Additionally for testing construct reliability all the Composite Reliability (CR) values ranging from $0.816-0.882$ were higher than 0.7 (Werts et al., 1974; Kline, 2010; Gefen et al., 2000) which adequately indicates that construct reliability is fulfilled as shown in Table 2. Therefore, the achieved Cronbach's alpha and CR for all constructs were considered to be sufficiently error-free.

Factor loading was used to test indicator reliability. High loadings on a construct indicate that the associated indicators seem to have much in common which is captured by the construct (Hair et al., 2017). Factor loadings $>0.50$ were considered to be very significant (Hair et al., 2010). The loadings for all items exceeded the recommended value of 0.5 as shown in Table 2. The loading for all items in the model has therefore, fulfilled all the requirements.

For testing convergent validity (the extent to which a measure correlates positively with alternative measures of the same construct) this study used the Average Variance Extracted (AVE) and it indicated that all AVE values were higher than the suggested value of 0.50 (Hair et al., 2010) ranging from $0.554-0.715$. The convergent validity for all constructs has been successfully fulfilled and adequate convergent validity exhibited as Table 2 shows.

The discriminant validity (the degree to which items differentiate among constructs or measure distinct concepts) of the measurement model was checked using 3 criteria, namely cross-loadings. Fornell-Larcker and the HeteroTrait-MonoTrait ratio (HTMT). According to Hair et al. (2017), the cross-loadings are typically the first approach to assess discriminant validity of the indicators. As shown in Table 3 the cross loading criterion fulfills the requirements because the indicators outer loadings on a construct were higher than all its cross-loadings with other constructs (bold values).

The results of discriminant validity by using the Fornell-Larcker criterion is shown in Table 4 where the square root of the AVEs on the diagonals as represented by the bolded values are higher than the correlations between constructs (corresponding row and column values). This indicates that the constructs are strongly

Table 2: Mean, standard deviation, loading, Cronbach's alpha, CR and AVE

\begin{tabular}{|c|c|c|c|c|c|c|}
\hline Constructs/item & Loading $(>0.5)$ & $\mathrm{M}$ & $\mathrm{SD}$ & Alpha $(>0.7)$ & $\mathrm{CR}(>0.7)$ & $\mathrm{AVE}(>0.5)$ \\
\hline \multicolumn{7}{|c|}{ Employee Creativity (EC) } \\
\hline $\mathrm{EC} 1$ & 0.927 & 4.34 & 1.377 & 0.837 & 0.877 & 0.554 \\
\hline $\mathrm{EC} 2$ & 0.578 & & & & & \\
\hline $\mathrm{EC} 3$ & 0.614 & & & & & \\
\hline EC4 & 0.936 & & & & & \\
\hline EC5 & 0.593 & & & & & \\
\hline EC6 & 0.726 & & & & & \\
\hline \multicolumn{7}{|c|}{ Expressing Confidence in high Performance (ECP) } \\
\hline ECP1 & 0.869 & 4.15 & 1.499 & 0.764 & 0.858 & 0.670 \\
\hline $\mathrm{ECP} 2$ & 0.763 & & & & & \\
\hline ECP3 & 0.819 & & & & & \\
\hline \multicolumn{7}{|c|}{ Enhancing the Meaningfulness of Work (EMW) } \\
\hline EMW1 & 0.891 & 4.04 & 1.707 & 0.803 & 0.882 & 0.715 \\
\hline EMW2 & 0.871 & & & & & \\
\hline EMW3 & 0.771 & & & & & \\
\hline \multicolumn{7}{|c|}{ Fostering Participation in Decision making (FPD) } \\
\hline FPD1 & 0.902 & 4.08 & 1.606 & 0.760 & 0.857 & 0.672 \\
\hline FPD2 & 0.894 & & & & & \\
\hline FPD3 & 0.634 & & & & & \\
\hline \multicolumn{7}{|c|}{ Providing Autonomy from Bur eaucratic constraints (PAB) } \\
\hline PAB1 & 0.885 & 4.11 & 1.661 & 0.795 & 0.867 & 0.684 \\
\hline PAB2 & 0.807 & & & & & \\
\hline PAB3 & 0.786 & & & & & \\
\hline \multicolumn{7}{|c|}{ Intrinsic Motivation (IM) } \\
\hline IM1 & 0.645 & 4.36 & 1.594 & 0.710 & 0.816 & 0.602 \\
\hline IM2 & 0.727 & & & & & \\
\hline IM3 & 0.928 & & & & & \\
\hline
\end{tabular}

$\mathrm{M}=$ Mean; SD = Standard Deviation, Alpha = Cronbach's alpha; CR = Composite Reliability, AVE = Average Variance Extracted; The measurement used is seven-point scale ranging from 1 (strongly disagree) to 7 (strongly agree); All the factor loadings of the individual items are statistically significant ( $<0.01$ ) 
Int. Business Manage., 13 (8): 318-330, 2019

Table 3: Results of discriminant validity by the cross loading

\begin{tabular}{lccc}
\hline Variables & EC & EL & IM \\
\hline EC1 & 0.927 & 0.689 & 0.655 \\
EC2 & 0.578 & 0.314 & 0.237 \\
EC3 & 0.614 & 0.323 & 0.336 \\
EC4 & 0.936 & 0.713 & 0.684 \\
EC5 & 0.593 & 0.273 & 0.304 \\
EC6 & 0.726 & 0.404 & 0.523 \\
ECP1 & 0.475 & 0.869 & 0.439 \\
ECP2 & 0.250 & 0.763 & 0.225 \\
ECP3 & 0.209 & 0.819 & 0.280 \\
EMW1 & 0.760 & 0.891 & 0.601 \\
EMW2 & 0.608 & 0.871 & 0.445 \\
EMW3 & 0.444 & 0.771 & 0.242 \\
FPD1 & 0.632 & 0.902 & 0.573 \\
FPD2 & 0.489 & 0.894 & 0.411 \\
FPD3 & 0.229 & 0.634 & 0.246 \\
PAB1 & 0.566 & 0.885 & 0.517 \\
PAB2 & 0.173 & 0.807 & 0.109 \\
PAB3 & 0.108 & 0.786 & 0.150 \\
IM1 & 0.236 & 0.250 & 0.645 \\
IM2 & 0.286 & 0.322 & 0.727 \\
IM3 & 0.763 & 0.702 & 0.928 \\
\hline EC: & . & &
\end{tabular}

EC: Employee Creativity, ECP: Expressing Confidence in high Performance, EMW: Enhancing the Meaningfulness of Work, FBD: Fostering participation in Decision making, PAB: Providing Autonomy from Bureaucratic constraints, EL: Empowering Leadership, IM: Intrinsic Motivation

Table 4: Results of discriminant validity by Fornell-Larcker criterion

\begin{tabular}{lllllll}
\hline Variables & EC & ECP & EMW & FPD & IM & PAB \\
\hline EC & 0.745 & & & & & \\
ECP & 0.409 & 0.818 & & & & \\
EMW & 0.733 & 0.359 & 0.846 & & & \\
FPD & 0.590 & 0.316 & 0.551 & 0.820 & & \\
IM & 0.666 & 0.408 & 0.532 & 0.529 & 0.776 & \\
PAB & 0.423 & 0.321 & 0.342 & 0.327 & 0.387 & 0.827 \\
\hline
\end{tabular}

Diagonals represent the square root of the average variance extracted while the other entries represent the correlations; EC: Employee Creativity, ECP: Expressing Confidence in high Performance, EMW: Enhancing the Meaningfulness of Work, FBD: Fostering participation in Decision making, PAB: Providing Autonomy from Bureaucratic constraints, IM: Intrinsic Motivation

related to their respective indicators compared to other constructs of the model (Fornell and Larcker, 1981; Chin, 1998), thus, suggesting a good discriminant validity (Hair et al., 2017). In addition, the correlation between exogenous constructs is $<0.85$ (Awang, 2014). Hence, the discriminant validity of all constructs is fulfilled.

There has been some criticism of the Fornell-Larcker et al. (2015) mentioned that it does not accurately reveal the lack of discriminant validity in common research situations. They have proposed an alternative technique which is the HeteroTrait-MonoTrait ratio (HTMT) of correlations based on the multitraitmultimethod matrix. This study assesses discriminant validity through HTMT. While the discriminant validity has a problem when the HTMT value is $>\mathrm{HTMT}_{0.90}$ value of 0.90 (Gold et al., 2001) or the $\mathrm{HTMT}_{0.85}$ value of 0.85 (Kline, 2010) all values as Table 5 shows were lower than the recommended value of 0.85 indicating that discriminant validity has been ascertained.
Table 5: Results of discriminant validity by HTMT

\begin{tabular}{lllllll}
\hline Variables & EC & ECP & EMW & FPD & IM & PAB \\
\hline EC & & & & & & \\
ECP & 0.466 & & & & & \\
EMW & 0.786 & 0.391 & & & & \\
FPD & 0.644 & 0.331 & 0.630 & & & \\
IM & 0.651 & 0.495 & 0.518 & 0.573 & & \\
PAB & 0.396 & 0.354 & 0.310 & 0.285 & 0.375 & \\
\hline
\end{tabular}

Key: EC: Employee Creativity, ECP: Expressing Confidence in high Performance, EMW: Enhancing the Meaningfulness of Work, FBD: Fostering participation in Decision making, PAB: Providing Autonomy from Bureaucratic constraints, IM: Intrinsic Motivation

Structural model assessment: Hair et al. (2017) suggested assessing the structural model by looking at the beta $(\mathrm{B}), \mathrm{R}^{2}$ and the corresponding t-values via. a bootstrapping procedure with a resample of 5,000 . Moreover, they recommend reporting the effect sizes $\left(\mathrm{f}^{2}\right)$ as well as the predictive relevance $\left(\mathrm{Q}^{2}\right)$. As (Sullivan and Feinn, 2012) argue that the $p$-value determine whether the effect exists but it does not reveal the size of the effect.

Hypothesis tests: The structural model assessment as shown in Fig. 2 and Table 6 provides the indication of the hypothesis tests with 3 out of the 3 hypothesis are supported. EL and IM significantly predict employee Creativity. Hence, $\mathrm{H}_{1-3}$ are accepted with $(\mathrm{b}=0.600$, $\mathrm{t}=25.985, \mathrm{p}<0.001),(\mathrm{b}=0.640, \mathrm{t}=37.762, \mathrm{p}<0.001)$ and $(b=0.284, t=10.129, p<0.001)$ respectively. Note that the standardized path coefficient indicates the strengths of the relationship between exogenous and endogenous constructs, so, the direct effects of EL on IM are much stronger than the influence of other variables. EL and IM are explaining $65.9 \%$ of the variance in $\mathrm{EC}$. The $\mathrm{R}^{2}$ values achieved an acceptable level of explanatory power as recommended by Cohen (1988) and Chin (1998) indicating a substantial model. This study also assessed effect sizes $\left(f^{2}\right)$. Effect size $f^{2}$ determines whether an exogenous latent construct has a substantial, moderate or weak impact on an endogenous latent construct (Gefen and Rigdon, 2011). Hair et al. (2017) recommend to test the change in the $\mathrm{R}^{2}$ value. Cohen (1988) suggested a guideline measure the magnitude of the $\mathrm{f}^{2}$ which is 0.35 (large effects), 0.15 (medium effects) and 0.02 (small effects). The result of $\mathrm{f}^{2}$ as Table 6 shows that three relationship with medium effect sizes. Further by using the blindfolding procedure this study examined the power of research proposed model regarding the predictive relevance. As recommended by Hair et al. (2017) the blindfolding procedure should use only on the endogenous constructs with a reflective measurement. If the value of $\mathrm{Q}^{2}$ is greater than 0 then the predictive relevance of the proposed model exists for a certain endogenous construct (Fornell et al., 2017). As Table 6 shows that all the values 


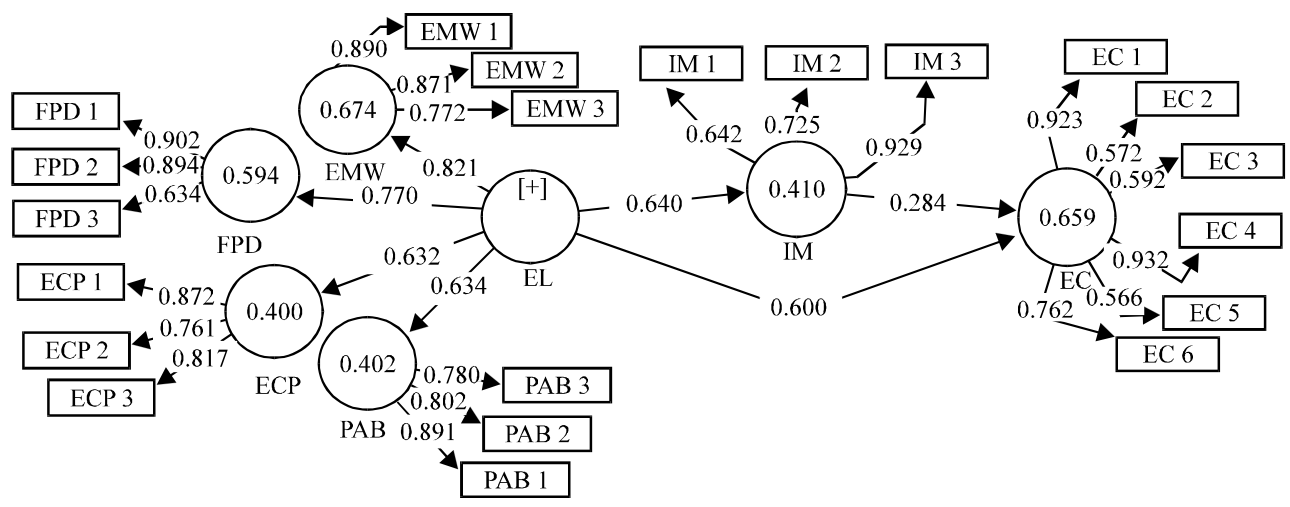

Fig. 2: PLS algorithm results; EC: Employee Creativity; ECP: Expressing Confidence in high Performance; EMW: Enhancing the Meaningfulness of work; FBD: Fostering participation in Decision making; PAB: Providing Autonomy from Bureaucratic constraints; EL: Empowering Leadership; IM: Intrinsic Motivation

Table 6: Structural path analysis result

\begin{tabular}{lllllllllll}
\hline Hypothesis & Relationship & $\mathrm{SD} \cdot$ & $\mathrm{SE}$ & t-values & p-values & Decision & $\mathrm{R}^{2}$ & $\mathrm{f}^{2}$ & $\mathrm{Q}^{2}$ & $\mathrm{VIF}^{2}$ \\
$\mathrm{H}_{1}$ & EL $>$ EC & 0.600 & 0.601 & 25.985 & 0.000 & Supported & 0.659 & 0.319 & 0.782 & 1.695 \\
$\mathrm{H}_{2}$ & EL $>$ IM & 0.640 & 0.641 & 37.762 & 0.000 & Supported & 0.410 & 0.203 & 0.284 & 1.000 \\
$\mathrm{H}_{3}$ & IM $>$ EC & 0.284 & 0.283 & 10.129 & 0.000 & Supported & & 0.319 & & 1.695 \\
\hline
\end{tabular}

EC: Employee Creativity, EL: Empowering Leadership, IM: Intrinsic Motivation

of $\mathrm{Q}^{2}$ greater than zero indicate that there is an adequate predictive relevance for the proposed model. For the $Q^{2}$ values, Hair et al. (2017) suggested values of 0.35 (large), 0.15 (medium) and 0.02 (small) as a relative measure of predictive relevance and the result of this study shows that the exogenous have one large predictive relevance and one with medium predictive relevance.

An issue of the multicollinearity could exist in any study which is not desirable, it means that the variance exogenous constructs explain in the endogenous construct are overlapping with each other and thus not each explaining unique variance in the endogenous variable ( $\mathrm{O}^{\prime}$ brien, 2007). To measure and assess the degree of multicollinearity, Variance Inflation Factor (VIF) widely used ( $O^{\prime}$ brien, 2007). There is cause for concern when the largest VIF is greater than 10 (Bowerman and O'Connell, 1990; Myers, 1990). And according to Hair et al. (2017) a multicollinearity issue exists when the largest VIF is greater than 5. Table 5 shows multicollinearity diagnostic through VIF which indicates that there is no evidence of significant multicollinearity among the study exogenous constructs because all VIF values are $<5$ ranging from 1.00-1.695. It means that the variance of exogenous constructs explains in the endogenous construct are not overlapping with each other.

Indirect hypothesis testing: According to the boot strapping's analysis there is a significant indirect impact in the relationship between EL and EC via. IM with a
Table 7: Bootstrapping the indirect effect of IM

$\mathrm{H}$ Constructs B-value $\mathrm{SE}$ t-values $\mathrm{p}$ values Decision
\begin{tabular}{lllllll}
\hline $\mathrm{H}_{2 \mathrm{a}}$ & EL->IM->EC & 0.182 & 0.181 & 11.008 & 0.000 & Supported \\
\hline
\end{tabular} (Preacher and Hayes, 2008); EC: Employee Creativity; EL: Empowering Leadership, IM: Intrinsic Motivation

Table 8: IPMA for Employ ee Creativity (EC)

\begin{tabular}{lcc} 
Latent constructs & $\begin{array}{l}\text { Total effect of the construct } \\
\text { organizational productivity (Importance) }\end{array}$ & $\begin{array}{c}\text { Index values } \\
\text { (Peformance) }\end{array}$ \\
EL & 0.953 & 67.211 \\
IM & 0.266 & 71.053 \\
\hline
\end{tabular}

EL: Empowering Leadership; IM: Intrinsic Motivation

t-value of 11.008 and p-vaue $<0.001$ as indicated by Preacher and Hayes (2008) that the mediation effect exist when the indirect impact of EL and $\mathrm{EC}$ via. IM with boot 95\% Cl: $[\mathrm{LL}=0.150, \mathrm{UL}=0.213]$, dos't straddle a zero in between. Hence, $\mathrm{H}_{2}$ a was supported (Table 7).

Importance-Performance Map Analysis (IPMA): This study ran an Importance-Performance Matrix Analysis (IPMA) as a post-hoc procedure in PLS using organizational performance as the outcome construct. The IPMA estimates the total effects represented by the importance of predecessor constructs in shaping the target construct (organizational performance) while their average latent variable scores represent their performance, the computation of the index values (performance scores) was accomplished by rescaling the latent constructs scores to a range of 100 (highest performance) down to 0 (lowest performance) (Hair et al., 2017). According to Ringle and Sarstedt (2016) IPMA enriches the PLS 


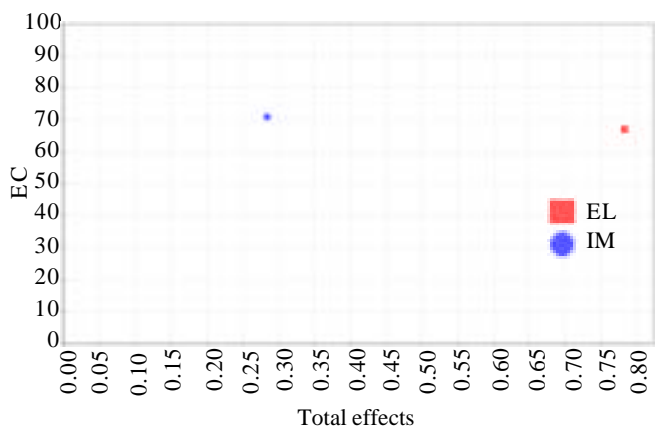

Fig. 3: IPMA (Priority Map) for Employee Creativity; EC: Employee Creativity; EL: Empowering Leadership; IM: Intrinsic Motivation

analysis results. Instead of only analyzing the path coefficients (i.e., the importance dimension), it also takes into consideration the average value of the latent constructs and their indicators (i.e., performance dimension). Table 8 shows the findings of importance (total effects) and performance (index values) used for the IPMA.

As shown in Fig. 3 this study plotted the total effects scores and index values in a priority map. It can be observed that EL is a very important factor in determining the EC due to its relatively higher importance value compared to other constructs in the proposed model. Nevertheless, the performance of this significant factor (EL) lagged behind the IM. According to Hair et al. (2017). The goal of IPMA is to identify predecessors that have a relatively high importance for the target construct (i.e., those that have a strong total effect) but also a relatively low performance (i.e., low average latent variable scores), the aspects underlying these constructs represent potential areas of improvement that may receive high attention. In sum in order to improve the $\mathrm{EC}$, the managerial activities should focus on enhancing the performance of EL.

The current study proposes that, empowering leadership is significantly having direct and indirect effect on hotel worker's creativity. EL influences EC indirectly through mediating variable of IM. EC correlates directly with IM and indirectly correlates with EL. Hence, forth increased EL will effect in improved IM which in turn increase EC. The recognition of IM as mediator in the causal relation between EL and EC help the ADNOC's management to create suitable strategies to enhance the behaviour of EL inside the ADNOC. As per the study's proposed model, the current study increaes our knowledge of the significant role of EL and IM to improve employee creativity behaviour at ADNOC, UAE and highlights relevant implications and suggestions for management and policy makers. The study found that EL positively affect EC among employees within the ADNOC in the United Arab Emirates this is supported by previous studies (Dong et al., 2015; Hon, 2010; Mo and Yu, 2017; Zhang et al., 2018; Z hang and Bartol, 2010; Zhang and Zhou, 2014). It is explained by the fact that the more the leadership of the organization is committed to establishing directions that will be aligned with all activities, teams and units that will ultimately be at the best interests of ADNOC service needs, besides encouraging cooperation, team work and social responsibility commitment, the more resource efficient the organization become and more likely to achieve optimal quality besides meeting its benchmarks on time to perform its duties. Additionally, ADNOC management should good example the essential organisational standards to support followers to learn and disguise and to have the feeling of membership and accomplishment. The role-modelling at the administration level services to increase IM and esteem from the subordinates. EL is a vital supervisor behaviour which positively improves staff's IM while increases EC indirectly.

Along with concentrating on improving EL, ADNOC administration would similarly give consideration to other antecedents of high IM with the aim to increase EC. With the aim to achieve better loyalty and involvement, ADNOC supervisors should support staff to attach their objectives to ADNOC objectives through implementing the strategy of management by objectives. Likewise it was found that EL positively affect IM among employees within the ADNOC in the United Arab Emirates, this is supported by previous studies (Hon, 2010; Zhang and Bartol, 2010; Lim et al., 2017) highlighted the importance of job engagement as a method to enhance favourable feelings and inspirations to the employees. Leaders have to obtain an appropriate jobsite for the staff members in order to enhance a sense of purpose at workplace.

Additionaly, it was found that $\mathrm{IM}$ positively affect $\mathrm{EC}$ among workers within the ADNOC in the UAE, this is supported by extant literature (Coelho et al., 2011; Hon, 2010; Zhang and Bartol, 2010). In order to face the fierce competition within the hospitality industry, hotel managers need to understand the work related behaviour because it was recognized as less subject and more stable to day-to-day fluctuation than job-satisfaction (Joo, 2010). The more IM the employees becomes and more likely to achieve optimal quality besides meeting its benchmarks on time to perform their duties. Employee who is affectively engaged to the job are less intention to leave the job and more creative (Lim et al., 2017). The sessions of mentoring and coaching will play a role in enhancing IM. Employee's empowerment in objective setting and decision-making helps to enhance worker's satisfaction and commitment. ADNOC leaders should implement $360^{\circ}$ feedback mechanizm to give staff with a voice in the hotel. 
The associations among EL and IM and EIB have been investigated widely. This study's results provide extra support for these causal relationships, mainly in ADNOC employee's and propose that EL is additional significant factor that indirectly affects these significant job outcomes. Similary, the results also revealed that EL has an indirect effect on EC via. IM, among employees within ADNOC in the United Arab Emirates which confirms the mediation role that IM has in this context. This concept has significant value for researchers interested in employee creativity. Moreover, the variance explained by the proposed model in the current study for EC among employees within the ADNOC in the United Arab Emirates is $65.9 \%$. Thus, ADNOC managers who want to foster better IM among employees of the ADNOC should take actions to confirm a more EL behaviour (Schwepker, 2001).

\section{CONCLUSION}

It is explained by the fact that, EL not only has a normative role by encouraging creativity behavior among ADNOC staff (Brown and Trevino, 2006, 2014; Brown et al., 2005) it also has a positive influence on in-role performance by strengthening subordinate's relationship with their supervisors and increasing employee's attachment to their organizations. The fact that EL indirectly affects follower's creativity behavior makes the case that $\mathrm{ADNOC}$ should define empowerment as a vital part of their leaders development strategies.

\section{LIMITATIONS}

Limitations and suggestions for future work: The first limitation concerns the generalizability of the findings, the targeted sampling of this study includes an employee working in ADNOC in the United Arab Emirates only. Another limitation is that data was gathered by cross-sectional and is not longitudinal in nature. The relationship between variables prescribed in the model of this study are highly case-dependent and thus they vary from organization to another, the model was implemented for an example organization which is ADNOC. As described in the introduction study of this research. Moreover, the exclusion of other organizational resources for instance, financial resources represents another limitation of the model. Although, such resources are necessary for organizations in the successful implementation of their capability-building plans it was decided that taking into account these organizational resources in the model will result in more unnecessary complications to the model and reduce from the main objectives of this research.

\section{IMPLICATIONS}

Implications for research: This research study has made use of the available literature of the concept of EL and IM by applying it to the context of an organization in the public sector in the United Arab Emirates to examine its role as a source of competitive advantage and its effect on the employee creativity. This research can be seen as an attempt to contribute to the understanding of the organizational performance that leads to a firm's enhanced productivity and thus enhanced competitive advantage (Rao, 2016). This concept has significant value for researchers interested in employee creativity. Moreover, the variance explained by the proposed model in the current study for employee creativity among workers within the ADNOC in the United Arab Emirates is 65.9\%. The predictive power of the model in this study has therefore, a higher ability to explain and predict employee creativity than obtained from some of the previous studies with different variances explained recorded for employee creativity (Hon, 2010; Zhang and Bartol, 2010). This research offers empirical support to the theoretical relevance of EL and IM to predict the creativity of organizations

Implication for practice: The present research is of significant for practitioners as it illustrates the importance of IM and EL. Although, a link of causality between the variables of this study cannot be clearly recognized because of the cross-sectional design, the results indicate that EL and IM are vital to facilitate and enhance the employee creativity. The order of this sequence should encourage organizations to put more emphasis on nurturing leader's empowering person dimension and moral manager one. Moreover, the implications of the key findings provide significant benefits not only for at ADNOC but also to the UAE local government authorities. Incorporating the findings, a number of practical implications were found such as promoting leaders empowering behavior as well as employee's IM which leads to improving employee creativity and quality of work. It is expected that key findings, especially, the proposed model will help in supporting the UAE government policy initiatives, especially, to increase creativity behavior as part of the job at all levels of organizations. The evidence shows a link between EL and better IM and creativity (Ahmad et al., 2016; Atmojo, 2015; Dhar, 2016; Karim and Noor, 2017; Restubog et al., 2010; Walumbwa et al., 2017). 


\section{REFERENCES}

Abd-Elaziz, M.E., W.M. Aziz, G.S. Khalifa and M. AbdelAleem, 2015. Determinants of Electronic Word of Mouth (EWOM) influence on hotel customers purchasing decision. Intl. J. Heritage Tourism Hospitality, 9: 194-223.

Abou-Shouk, M.A. and G.S. Khalifa, 2017. The influence of website quality dimensions on E-purchasing behaviour and e-loyalty: A comparative study of Egyptian travel agents and hotels. J. Travel Tourism Marketing, 34: 608-623.

Ahearnen, M., J. Mathieu and A. Rapp, 2005. To empower or not to empower your sales force?. An empirical examination of the influence of leadership empowerment behavior on customer satisfaction and performance. J. Applied Psychol., 90: 945-955.

Ahmad, J., M.R. Athar and M. Hussain, 2016. Linking personality traits with job performance mediating role of organizational commitment: An empirical evidence. NUML. Intl. J. Bus. Manage., 11: 1-11.

Alsaadi, T.A.R.M., A.E. Abuelhassan, G.S.A. Khalifa, A. Ameen and M. Nusari, 2019. Empowering leadership predictors for employees creativity. Int. Bus. Manage., 13: 119-129.

Amabile, T.M., 1988. A model of creativity and innovation in organization. Res. Organ. Behav., 10: 123-167.

Amabile, T.M., 1993. Motivational synergy: Toward new conceptualizations of intrinsic and extrinsic motivation in the workplace. Hum. Resour. Manage. Rev., 3: 185-201

Amabile, T.M., E.A. Schatzel, G.B. Moneta and S.J. Kramer, 2004. Leader behaviors and the work environment for creativity: Perceived leader support. Leadership Q., 15: 5-32.

Amabile, T.M., R. Conti, H. Coon, J. Lazenby and M. Herron, 1996. Assessing the work environment for creativity. Acad. Manage. J., 39: 1154-1184.

Anderson, J.C. and D.W. Gerbing, 1988. Structural equation modeling in practice: $\mathrm{A}$ review and recommended two-step approach. Psychol. Bull., 103: 411-423.

Atmojo, M., 2015. The influence of transformational leadership on job satisfaction, organizational commitment and employee performance. Int. Res. J. Bus. Stud., 5: 113-128.

Awang, Z., 2014. Structural Equation Modeling Using AMOS. Universiti Teknologi MARA Publication Center, Shah Alam, Malaysia,.

Badran, N. and G. Khalifa, 2016. Diversity management: Is it an important issue in hotel industry in Egypt?. Intl.
J. Heritage Tourism Hospitality, 7: 275-286.

Baer, M., G.R. Oldham and A. Cummings, 2003. Rewarding creativity: When does it really matter?. Leadersh. Q., 14: 569-586.

Barclay, D., C. Higgins and R. Thompson, 1995. The Partial Least Squares (PLS) approach to causal modeling: Personal computer adoption and use as an illustration. Technol. Stud., 2: 285-309.

Baruch, Y. and B.C. Holtom, 2008. Survey response rate levels and trends in organizational research. Hum. Relat., 61: 1139-1160.

Bass, B.M., 1985. Leadership and Performance beyond Expectations. The Free Press, New York, ISBN-13: 978-0029018101, Pages: 256.

Bowerman, B.L. and R.T. O'Connell, 1990. Linear Statistical Models: An Applied Approach. 2nd Edn., PWS-Kent Pub. Co., New York, USA., ISBN:9780534229856, Pages: 1024.

Boyatzis, R.E., S.S. Cowen and D.A. Kolb, 1995. Innovation in Professional Education: Steps on a Journey from Teaching to Learning. 1st Edn., JosseyBass Publishes, San Francisco, California, ISBN13:978-0787900328, Pages: 280.

Brislin, R.W., 1970. Back-translation for cross-cultural research. J. Cross Cult. Psychol., 1: 185-216.

Brown, M.E. and L.K. Trevino, 2006. Ethical leadership: A review and future directions. Leadership Q., 17: 595616.

Brown, M.E. and L.K. Trevino, 2014. Do role models matter? An investigation of role modeling as an antecedent of perceived ethical leadership. J. Bus. Ethics, 122: 587-598.

Brown, M.E., L.K. Trevino and D.A. Harrison, 2005. Ethical leadership: A social learning perspective for construct development and testing. Org. Behav. Hum. Decis. Process., 97: 117-134.

Cable, D.M. and D.S. DeRue, 2002. The convergent and discriminant validity of subjective fit perceptions. J. Applied Psychol., 87: 875-884.

Cai, W., E.I. Lysova, S.N. Khapova and B.A.G. Bossink, 2018. Does entrepreneurial leadership foster creativity among employees and teams? The mediating role of creative efficacy beliefs. J. Bus. Psychol., 1: 1-15.

Chen, G., B.L. Kirkman, R. Kanfer, D. Allen and B. Rosen, 2007. A multilevel study of leadership, empowerment and performance in teams. J. Appl. Psychol., 92: 331 346.

Chin, W.W., 1998a. Commentary: Issues and opinion on structural equation modeling. MIS Q., 22: 7-16.

Chin, W.W., 1998b. The partial least squares approach to structural equation modeling. Modern Methods Bus. Res., 295: 295-336. 
Coelho, F., M. Augusto and L.F. Lages, 2011. Contextual factors and the creativity of frontline employees: The mediating effects of role stress and intrinsic motivation. J. Retailing, 87: 31-45.

Cohen, J., 1988. Statistical Power Analysis for the Behavioral Sciences. 2nd Edn., Routledge, Hillsdale, NJ., USA., ISBN-13: 9780805802832 , Pages: 567.

Deci, E.L. and R.M. Ryan, 1985. Intrinsic motivation and Self-Determination in Human Behavior. Springer, New York Pages: 388

Dhar, R.L., 2016. Ethical leadership and its impact on service innovative behavior: The role of LMX and job autonomy. Tourism Manage., 57: 139-148.

Dong, Y., H. Liao, A. Chuang, J. Zhou and E.M. Campbell, 2015. Fostering employee service creativity: Joint effects of customer empowering behaviors and supervisory empowering leadership. J. Appl. Psychol., 100: 1364-1380.

Dong, Y., K.M. Bartol, Z.X. Zhang and C. Li, 2017. Enhancing employee creativity via. individual skill development and team knowledge sharing: Influences of dual-focused transformational leadership. J. Organizational Behav., 38: 439-458.

Fornell, C. and D.F. Larcker, 1981. Evaluating structural equation models with unobservable variables and measurement error. J. Marketing Res., 18: 39-50.

Fornell, C. and J. Cha, 1994. Partial Least Squares. In: Advanced Methods of Marketing Research, Bagozzi, R.P. (Ed.). Blackwell Publisher, Cambridge, England, pp: $52-78$.

Gefen, D., D. Straub and E.E. Rigdon, 2011. An update and extension to SEM guidelines for admnistrative and social science research. MIS. Q., 35: 3-14.

Gefen, D., D. Straub and M.C. Boudreau, 2000. Structural equation modeling and regression: Guidelines for research practice. Commun. Assoc. Inf. Syst., 4: 1-77.

Gold, A.H., A. Malhotra and A.H. Segars, 2001. Knowledge management: An organizational capabilities perspective. J. Manage. Inform. Syst., 18: 185-214.

Hackman, J.R. and G.R. Oldham, 1975. Development of the job diagnostic survey. J. Applied Psychol., 60: 159170 .

Hair Jr, J.F., W.C. Black, B.J. Babin and R.E. Anderson, 2010. Multivariate Data Analysis. 7th Edn., Pearson Publishing Company, London, UK., ISBN-13:9780138132637, Pages: 816 .

Hair, Jr., J.F., G.T.M. Hult, C.M. Ringle and M. Sarstedt, 2017. A Primer on Partial Least Squares Structural Equation Modeling (PLS-SEM). 2nd Edn., Sage Publisher, Thousand Oaks, California.
Henseler, J., C.M. Ringle and M. Sarstedt, 2015. A new criterion for assessing discriminant validity in variance-based structural equation modeling. $\mathrm{J}$. Acad. Marketing Sci., 43: 115-135.

Hon, A.H.Y., 2010. Shaping environments conductive to creativity: The role of intrinsic motivation. Cornell Hospitality Q., 53: 53-64.

Javed, B., A.A. Khan, S. Bashir and S. Arjoon, 2017. Impact of ethical leadership on creativity: The role of psychological empowerment. Curr. Issues Tourism, 20: 839-851

Joo, B.K., 2010. Organizational commitment for knowledge workers: The roles of perceived organizational learning culture, leader-member exchange quality and turnover intention. Hum. Resour. Dev. Q., 21 : 69-85.

Jung, D.I., C. Chow and A. Wu, 2003. The role of transformational leadership in enhancing organizational innovation: Hypothesis and some preliminary findings. Leadersh. Q., 14: 525-544.

Kannan, V.R. and K.C. Tan, 2005. Just in time, total quality management and supply chain management: Understanding their linkages and impact on business performance. Omega, 33: 153-162.

Karim, N.H.A. and N.H.N.M. Noor, 2017. Evaluating the psychometric properties of Allen and Meyers organizational commitment scale: A cross cultural application among Malaysian academic librarians. Malaysian J. Library Inf. Sci., 11: 89-101.

Khalefa, G.S.A., 2015. Ethnic restaurants' meal experience: Egyptian customers' perceptions. Intl. J. Heritage Tourism Hospitality, 9: 92-112.

Khalifa, G.S. and M.A. Abou-Shouk, 2014. Investigating the success factors of hotel websites: The case of Egyptian hotels. Asia Pac. J. Innovation Hospitality Tourism, 3: 131-151.

Khalifa, G.S.A. and M. Hewedi, 2016. Factors affecting hotel website purchasing intentions: Evidence from Egypt. J. Faculty Tourism Hotels, Fayoum Univ., 8: 50-69.

Kline, R.B., 2010. Principles and Practice of Structural Equation Modeling. 3rd Edn., The Guilford Press, New York, USA., ISBN-13: 9781606238769 , Pages: 427.

Krejcie, R.V. andD.W. Morgan, 1970. Determining sample size for research activities. Educ. Psychol. Meas., 30: 607-610.

Lee, B.C., J.O. Yoon andI. Lee, 2009. Learner's acceptance of e-Learning in South Korea: Theories and results. Comput. Educ., 53: 1320-1329.

Lim, A.J.P., J.T.K. Loo and P.H. Lee, 2017. The impact of leadership on turnover intention: The mediating role of organizational commitment and job satisfaction. J. Appl. Struct. Equation Model., 1: 27-41. 
Liu, D., K. Jiang, C.E. Shalley, S. Keem and J. Zhou, 2016. Motivational mechanisms of employee creativity: A meta-analytic examination and theoretical extension of the creativity literature. Organizational Behave. Hum. Decis. Processes, 137: 236-263.

McGraw, K.O. and J. Fiala, 1982. Undermining the Zeigarnik effect: Another hidden cost of reward. J. Personality, 50: 58-66.

Mo, Z. and Y. Yu, 2017. The Mechanism of Empowering Leadership's Effect on Employee Creativity in Dingtalk Alibaba Context. In: Proceedings of the Fourth International Forum on Decision Sciences, Li, $\mathrm{X}$. and X. Xu (Eds.). Springer, Singapore, ISBN:978981-10-2919-6, pp: 99-117.

Mohamed, M.S., G.S.A. Khalifa, M. Nusari, A. Ameen and A.H. Al-Shibami et al., 2018. Effect of organizational excellence and employee performance on organizational productivity within healthcare sector in the UAE. J. Eng. Appl. Sci., 13: 6199-6210.

Mohamud, S.S., G.S.A. Khalifa, A.E. Abuelhassan and S. Kaliyamoorthy, 2017. Investigating the antecedents of coffee shop customer's behavioral intentions in Kuala Lumpur. Intl. J. Recent Trends Bus. Tourism, 1: 1-14.

Morsy, M.A., G.S. Ahmed and N.A.A. Ali, 2016. Impact of effective training on employee performance in hotel establishments. Intl. J. Heritage Tourism Hospitality, 10: 92-109.

Mumford, M.D., G.M. Scott, B. Gaddis and J.M. Strange, 2002. Leading creative people: Orchestrating expertise and relationships. Leadersh. Q., 13: 705-750.

Myers, R.H., 1990. Classical and Modern Regression with Applications. 2nd Edn., Duxbury/Thompson Learning, Boston, USA., ISBN-13: 9780534380168 , Pages: 488.

Nunnally, J.C. and I.H. Bernstein, 1994. Psychometric Theory. 3rd Edn., McGraw-Hill, New York, USA., ISBN-13: 978-0070478497, Pages: 736.

O'Brien, R.M., 2007. A caution regarding rules of thumb for variance inflation factors. Qual. Quantity, 41: 673690.

Oldham, G.R. and A. Cummings, 1996. Employee creativity: Personal and contextual factors at work. Acad. Manage. J., 39: 607-634.

Prather, C., 2010. Manager's Guide to Fostering Innovation and Creativity in Teams. McGraw-Hill, Madison, Wisconsin,

Preacher, K.J. and A.F. Hayes, 2008. Asymptotic and resampling strategies for assessing and comparing indirect effects in multiple mediator models. Behav. Res. Methods, 40: 879-891.
Qoura, O. and G.S.A. Khalifa, 2016. The impact of reputation management on hotel image among internal customers: The case of egyptian hotels. Intl. J. Heritage Tourism Hospitality, 7: 261-274.

Rao, M.S., 2016. Collaborate to build effective teams to achieve organizational excellence and effectiveness. Ind. Commer. Training, 48: 24-28.

Reiter-Palmon, R. And J.J. Illies, 2004. Leadership and creativity: Understanding leadership from a creative problem-solving perspective. Leadersh. Q., 15: 55-77.

Restubog, S.L.D., P. Bordia, R.L. Tang and S.A. Krebs, 2010. Investigating the moderating effects of leadermember exchange in the psychological contract breach-employee performance relationship: A test of two competing perspectives. Br. J. Manage., 21: 422437.

Ringle, C.M. and M. Sarstedt, 2016. Gain more insight from your PLS-SEM results: The importanceperformance map analysis. Ind. Manage. Data Syst., 116: 1865-1886.

Ringle, C.M., S. Wende and J.M. Becker, 2014. Smartpls 3. SmartPLS, Hamburg, Germany,

Schumacker, R.E. and R.G. Lomax, 2004. A beginner's Guide to Structural Equation Model. 2nd Edn., Lawrence Erlbaum Associates, M ahwah, New YorK.

Schwepker Jr., C.H., 2001. Ethical climate's relationship to job satisfaction, organizational commitment and turnover intention in the salesforce. J. Bus. Res., 54: $39-52$.

Shalley, C.E. and L.L. Gilson, 2004. What leaders need to know: A review of social and contextual factors that can foster or hinder creativity. Leadership Q., 15: 3353.

Shalley, C.E., J. Zhou and G.R. Oldham, 2004. The effects of personal and contextual characteristics on creativity: Where should we go from here? J. Manage., 30: 933-958.

Sharma, P.N. and B.L. Kirkman, 2015. Leveraging leaders: A literature review and future lines of inquiry for empowering leadership research. Group Organ. Manage., 40: 193-237.

Simon, H.A., 1967. Motivational and emotional controls of cognition. Psychol. Rev., 74: 29-39.

Srivastava, A., K.M. Bartol and E.A. Locke, 2006. Empowering leadership in management teams: Effects on knowledge sharing, efficacy and performance. Acad. Manage. J., 49: 1239-1251.

Sullivan, G.M. and R. Feinn, 2012. Using effect size-or why the p-value is not enough. J. Graduate Med. Educ., 4: 279-282. 
Tabachnick, B.G. and L.S. Fidell, 2012. Using Multivariate Statistics. 6th Edn., Pearson Education, ýLondon, England, ISBN:9780205849574, Pages: 983.

Tierney, P., S.M. Farmer and G.B. Graen, 1999. An examination of leadership and employee creativity: The relevance of traits and relationships. Personnel Psychol., 52: 591-620.

Utman, C.H., 1997. Performance effects of motivational state: A meta-analysis. Personality Soc. Psychol. Rev., 1: 170-182.

Walumbwa, F.O., C.A. Hartnell and E. Misati, 2017. Does ethical leadership enhance group learning behavior? Examining the mediating influence of group ethical conduct, justice climate and peer justice. J. Bus. Res., 72: 14-23.

Werts, C.E., R.L. Linn and K.G. Joreskog, 1974. Intraclass reliability estimates: Testing structural assumptions. Educ. Psychol. Meas., 34: 25-33.

Wiersma, U.J., 1992. The effects of extrinsic rewards in yntrinsic motivation: A meta analysis. J. Occup. Organiz. Psychol., 65: 101-114.

Woodman, R.W., J.E. Sawyer and R.W. Griffin, 1993. Toward a theory of organizational creativity. Acad. Manage. Rev., 18: 293-321.
Yidong, T. and L. Xinxin, 2013. How ethical leadership influence employee's innovative work behaviour: A perspective of intrinsic motivation. J. Bus. Ethics, 116: 441-455.

Zhang, S., X. Ke, X.H.F. Wang and J. Liu, 2018. Empowering leadership and employee creativity: A dual-mechanism perspective. J. Occup. Organizational Psychol., 91: 896-917.

Zhang, X. and J. Zhou, 2014. Empowering leadership, uncertainty avoidance, trust and employee creativity: Interaction effects and a mediating mechanism. Organizational Behav. Hum. Decis. Processes, 124: 150-164.

Zhang, X. and K.M. Bartol, 2010. Linking empowering leadership and employee creativity: The influence of psychological empowerment, intrinsic motivation and creative process engagement. Acad. Manage. J., 53: 107-128.

Zhao, L., Y. Lu, B. Wang and W. Huang, 2011. What makes them happy and curious online? An empirical study on high school student's Internet use from a self determination theory perspective. Comput. Educ., 56: 346-356.

Zopiatis, A. and A.L. Theocharous, 2018. PRAXIS: The determining element of innovation behavior in the hospitality industry. J. Hospitality Tourism Manage., 35: 9-16. 